\title{
Calcium-binding proteins immunoreactivity in the human subcortical and cortical visual structures
}

\author{
G. LEUBA AND K. SAINI \\ University Psychogeriatrics Hospital, $\mathrm{CH}-1008$ Lausanne-Prilly, Switzerland
}

(ReCeived July 5, 1995; ACCEPTED March 1, 1996)

\begin{abstract}
The distribution of neurons and fibers immunoreactive (ir) to the three calcium-binding proteins parvalbumin (PV), calbindin D-28k (CB), and calretinin (CR) was studied in the human lateral geniculate nucleus (LGN), lateral inferior pulvinar, and optic radiation, and related to that in the visual cortex. In the LGN, PV, CR, and CB immunoreactivity was present in all laminae, slightly stronger in the magnocellular than in the parvocellular laminae for $C B$ and $C R$. PV-ir puncta, representing transversally cut axons, and CR-ir fibers were revealed within the laminae and interlaminar zones, and just beyond the outer border of lamina 6 in the geniculate capsule. In the optic radiation both PV-and CR-immunoreactive neurons, puncta, and fibers were present. $\mathrm{CB}$ immunoreactivity was revealed in neurons of all laminae of the lateral geniculate nucleus, including S lamina and interlaminar zones. There were hardly any CB-ir puncta or fibers in the laminae, interlaminar zones, geniculate capsule, or optic radiation. In the lateral inferior pulvinar, immunoreactive neurons for the three calcium-binding proteins were present in smaller number than in the LGN, as well as PV-ir puncta and CR-ir fibers within the nucleus and in the pulvinar capsule. In the white matter underlying area 17 , fibers intermingled with a few scattered neurons were stained for both PV and $C R$, but very rarely for CB. These fibers stopped at the limit between areas 17 and 18 . Area 17 showed a dense plexus of PV-ir puncta and neurons in the thalamo-receptive layer IV and CR-ir puncta and neurons both in the superficial layers I-II, IIIC, and in layer VA. Cajal-Retzius CR-ir neurons were present in layer I. CB-ir puncta were almost confined to layer I-III and CB-ir neurons to layer II. Finally the superior colliculus exhibited mostly populations of PV and CR pyramidal-like immunoreactive neurons, mainly in the intermediate tier. These data suggest that in the visual thalamus most calcium-binding protein immunoreactive neurons project to the visual cortex, while in the superior colliculus a smaller immunoreactive population represent projection neurons.
\end{abstract}

Keywords: Calcium-binding proteins, Lateral geniculate nucleus, Visual cortex, Superior colliculus, Human

\section{Introduction}

Although the role of calcium-binding proteins is not yet completely understood, the cellular distribution of parvalbumin (PV) and calbindin D-28k (CB) has been extensively studied during the last few years in the brain of rodents and monkeys but comparatively less in the human brain. In the cerebral cortex of monkeys, PV- and CB-positive neurons have been described as two nonoverlapping populations of GABAergic interneurons (Blümcke et al., 1990; Blümcke \& Celio, 1992; Hendry \& Carder, 1993; Jones, 1993). In most areas, GABAergic cells immunoreactive (ir) for parvalbumin are chandelier and basket interneurons concentrated in layers $\mathrm{III}$ and IV, while those immunoreactive for calbindin are mainly double bouquet interneurons distributed in layers II and III, less in layers V-VI (Jones, 1993). In addition, PV immunoreactivity reveals a zone of thalamic afferents in lamina IV of the primary visual cortex

Reprint requests to: G. Leuba, University Psychogeriatrics Hospital, CH-1008 Lausanne-Prilly, Switzerland.
(Blümcke et al., 1991; DeFelipe \& Jones, 1991). In the human visual cortex, the distribution of both PV-ir and CB-ir interneurons is comparable to that in the monkey (Blümcke et al., 1990; Hendry \& Carder, 1993), although PV-ir interneurons are about $11 \%$ of the neuronal population in the monkey and only about $7 \%$ in human (Blümcke et al., 1990). The distribution of calretinin (CR)-positive interneurons has been less extensively studied than that of PV-ir and CB-ir interneurons in the cerebral cortex. However, a population of CR-ir cells has been described in the primary visual cortex of dolphins and humans; in the latter, these cells, mainly bipolar or fusiform in shape, are distributed largely in superficial layers II to IVA, while large multipolar cells are observed in layers I and VI (Glezer et al., 1992).

In the thalamus of Macaque monkeys, and more specifically in the lateral geniculate nucleus (LGN) and pulvinar, there are both PV-ir and CB-ir neuronal populations, with the CB-ir neurons localized exclusively in the interlaminar and $S$ laminae (Jones \& Hendry, 1989). The presence of a large number of PV-positive asymmetric synaptic contacts in the thalamo-recip- 
ient layer IV of the primary visual cortex suggests that these afferents derive from the PV-ir neurons located in the LGN (Blümcke et al., 1991; DeFelipe \& Jones, 1991). In the prosimian Galago, a complementary pattern of PV-ir and CB-ir neurons has also been described in the LGN, differentiating parallel visual pathways to the visual cortex (Diamond et al., 1993; Casagrande, 1994; Johnson \& Casagrande, 1995). The presence of CB-ir neurons in the koniocellular layers, receiving fibers both from the retina and from the superior colliculus, suggests that calbindin is a marker for the LGN cells that belong to the third visual pathway, the $\mathrm{K}$ pathway, resembling the $\mathrm{W}$ pathway in cat (Casagrande, 1994). Furthermore, combined retrograde- and double-labeling experiments have shown that both PV-ir and CB-ir LGN neurons are projecting to different parts of the visual cortex, none being GABAergic (Johnson \& Casagrande, 1995). Finally in the lateral inferior pulvinar (LIP), a chemoarchitectonic subdivision based on PV and CB immunocytochemistry was demonstrated, suggesting that the PV-positive neurons were the fast firing cells projecting to the medial temporal area MT in the monkey, while the CB-positive cells were scarce (Cusick et al., 1993). PV-ir and CB-ir neurons seem thus to be projection neurons in the thalamus of monkeys, while they are mostly GABAergic interneurons in the cerebral cortex.

CR-ir neurons have not, to our knowledge, been demonstrated in the thalamus of primates, but in the retina and LGN of different species (Pasteels et al., 1990) and in the optic tract and LGN of rodents (Jacobowitz \& Winsky, 1991; Arai et al., 1992), suggesting that there may be a CR-positive projection from the retina to the $L G N$. In the present paper, we study the distribution of $P V, C B$, and $C R$ in the $L G N$, LIP, optic radiation (OR), and superior colliculus (SC) of humans, and compare it to that in the primary visual cortex and underlying white matter.

\section{Materials and methods}

Tissue blocks were taken from the brains of ten normal human adults, both males and females, without neurological disease (Table 1). The brains were fixed by submersion in $10 \%$ formaldehyde or, for some of them, frozen directly at autopsy $\left(-70^{\circ} \mathrm{C}\right)$. The postmortem delay was between 10 and $20 \mathrm{~h}$ and the time

Table 1. Description of the 10 cases used in this study ${ }^{a}$

\begin{tabular}{rrrl}
\hline \hline Cases & Age & Sex & \multicolumn{1}{c}{ Cause of death } \\
\hline 1 & 30 & M & myocardial infarct \\
2 & 48 & M & myocardial infarct \\
3 & 59 & M & esophageal carcinoma \\
4 & 65 & F & accident \\
5 & 71 & M & pancreatic carcinoma \\
6 & 76 & M & bronchial carcinoma \\
7 & 78 & M & thrombosis \\
8 & 82 & F & hypothermia \\
9 & 84 & M & glioblastoma \\
10 & 96 & M & pneumonia
\end{tabular}

${ }^{a}$ Age is in years; sex: $(M)$ male, $(F)$ female; cause of death is not neurological, except for case 9 , whose glioblastoma was not in the visual region. Postmortem delay between 10 and $20 \mathrm{~h}$ (see Methods). of fixation generally did not exceed 1 year. However, two cases with a slightly longer fixation gave excellent results. Blocks were dissected out from the middle of the calcarine sulcus (area 17), from the thalamic region containing the LGN and LIP and from the mesencephalon containing the SC. Frozen $50 \mu \mathrm{m}$ sections were cut in a frontal plane and kept at $4^{\circ} \mathrm{C}$ in cold Tris-buffered saline (TBS $0.1 \mathrm{M}, \mathrm{pH} 7.3$ ) until immunohistochemical processing.

Immunohistochemical staining was performed using three different primary antibodies: Anti-Parvalbumin 235 mouse monoclonal IgG1, Anti-Calbindin D-28K mouse monoclonal 300 IgG1, and Anti-Calretinin 7696 rabbit polyclonal donated by M.R. Celio. Free-floating sections were incubated for 3 days at $4^{\circ} \mathrm{C}$ either with PV, CR (dilution 1:1000), or CB (dilution $1: 500$ ) in TBS buffer containing $10 \%$ calf serum and $0.1 \%$ Triton X100. After incubation with the primary antibody, the sections were rinsed in TBS $(6 \times 5 \mathrm{~min})$ and incubated for $2 \mathrm{~h}$ at room temperature in biotinylated antimouse $\operatorname{lgG}$ (for $\mathrm{PV}$ and $\mathrm{CB}$ ) or antirabbit IgG (for CR) from Vector Laboratories, Burlingame, CA (dilution 1:200 in TBS containing 10\% calf serum). Sections were rinsed again in TBS $(6 \times 5 \mathrm{~min})$ and incubated for $3 \mathrm{~h}$ at room temperature in avidin-biotin-peroxidase complex $(4.5 \mu \mathrm{l} / \mathrm{ml}$ in TBS containing $10 \%$ calf serum). The bound peroxidase was revealed by incubating the sections for $10-20 \mathrm{~min}$ at room temperature in a mixture of $0.05 \%$ 3,3-diaminobenzidine (Sigma Chemical Co., St. Louis, MO) and $0.01 \% \mathrm{H}_{2} \mathrm{O}_{2}$ in 0.05 M TBS. Immunoreactive cells and neuropil were visualized under brightfield illumination using a Zeiss Axioplan microscope.

\section{Results}

Lateral geniculate nucleus, pregeniculate nucleus, and optic radiation (Figs. 1-3; Table 2)

In the LGN, we found PV-ir neurons in all of the laminae and the intensity of staining did not depend on the age of the subjects (Figs. 1A-1D). Neuronal perikarya were diffusely stained without clear dendritic arborization in both magnocellular (M) and parvocellular (P) laminae (Figs. 1A-1D, 3A, and 3B). Interlaminar zones were mostly free of $\mathrm{PV}$-ir neurons, although a few positive neurons were scattered close to the laminar borders. Numerous PV-ir puncta, which represent axonal and dendritic terminals (see Discussion), were distributed across the laminae and the interlaminar zones, as well as in the geniculate capsule at the outer border of lamina 6 (Figs. 3A-3C). CR-ir neurons were also observed in all $M$ and $P$ laminae, diffusely marked with a stronger staining in the $M$ than in the $P$ laminae (Figs. 2A, 2C, and 3D). In the interlaminar zones, only neurons close to the borders showed CR immunoreactivity. CR-ir puncta were present in the interlaminar zones (Fig. 3D), while CR-ir fibers were observed mainly in the geniculate capsule (Fig. 3E). CB-ir neurons were present in all laminae with well-marked cell bodies but poorly marked dendrites. Magnocellular neurons appeared to be slightly more intense than the parvocellular ones but this difference was not as clear as for CR (compare Figs. 2A, 2C with Figs. 2B, 2D). Scattered well-marked CB-ir neurons but no fibers or puncta were observed in the interlaminar zones or in the geniculate capsule (Figs. 2B, 2D, 3F, and 3G). When an $\mathrm{S}$ lamina was present in our sections, it showed a similar $\mathrm{CB}$ immunostaining as the magnocellular laminae 1 and 2 (Fig. 2D).

In the pregeniculate nucleus, which lies in close vicinity to the LGN dorsally and caudally, we found rare CB-ir neurons, 

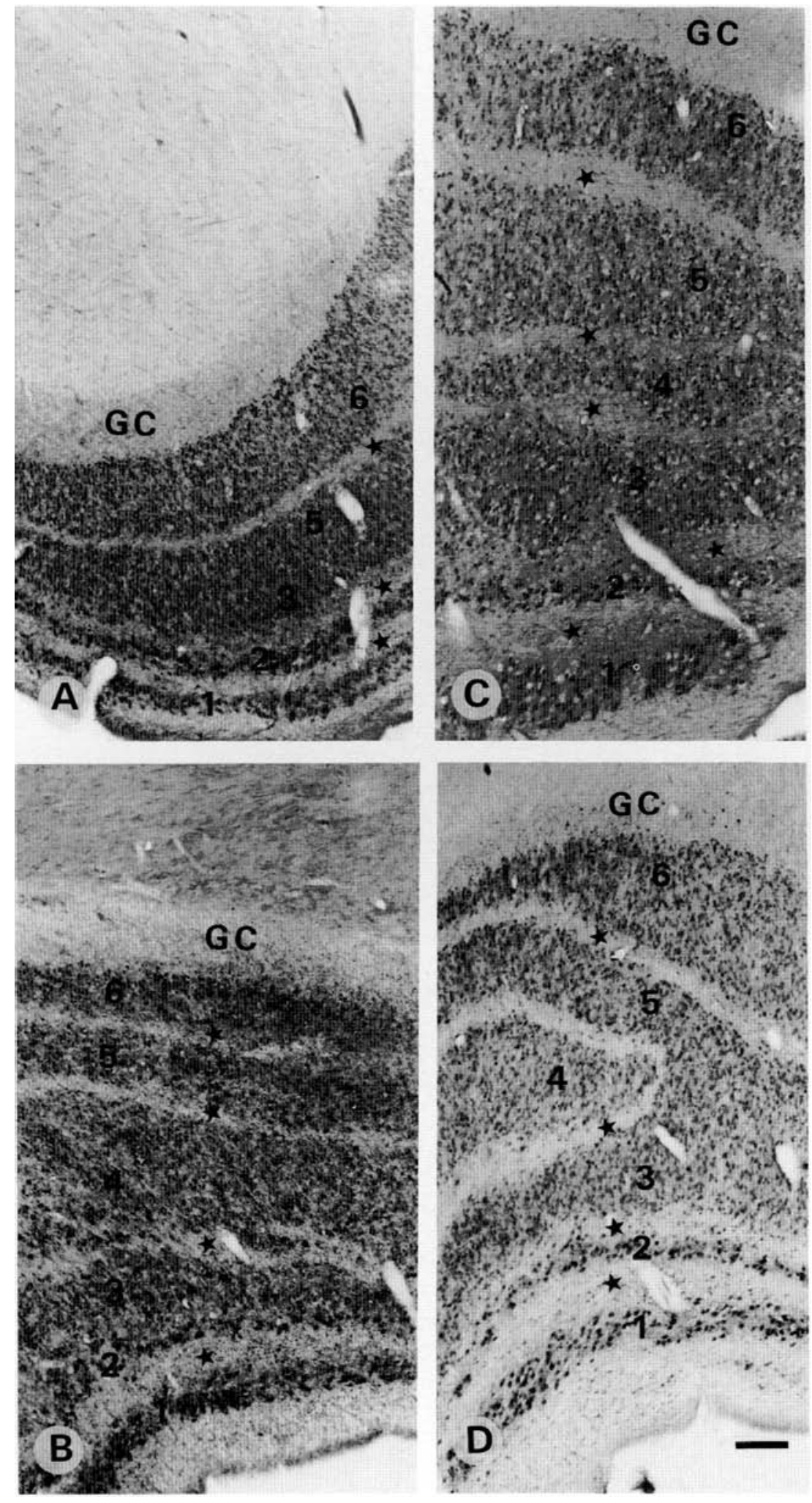

Fig. 1. Light micrographs demonstrating PV immunoreactivity in the human LGN from different cases. (A) case 6, age 76 years (see Table 1); (B) case 9, age 84 years; (C) case 5, age 71 years; and (D) case 1, age 30 years. PV immunoreactivity in $M$ laminae 1 and 2 appears almost similar to that in $P$ laminae 3-6 and the intensity of immunostaining is not different between young and old cases. At the outer border of lamina 6, the geniculate capsule (GC) shows PV-ir puncta. Puncta are also observed within the interlaminar zones $\left(^{*}\right)$ and their density varies slightly from one case to the other. Scale bar in A-D $=500 \mu \mathrm{m}$.

but a few large strongly PV-ir and CR-ir neurons (Fig. 3E), mostly multipolar and bipolar in shape.

Finally in the OR, we found many scattered and well-marked PV-ir and CR-ir interstitial neurons as well as well-defined PV-ir and $\mathrm{CR}$-ir fiber bundles. $\mathrm{CB}$-ir neurons and fibers were only few in the optic radiation.

\section{Lateral inferior pulvinar (Fig. 4; Table 2)}

In the lateral inferior pulvinar (LIP), the immunostaining of calcium-binding proteins was similar to that in the LGN but the proportion of stained neurons was less. PV-ir neurons as well as puncta were well marked (Figs. 4A and 4B). CR-ir neurons 

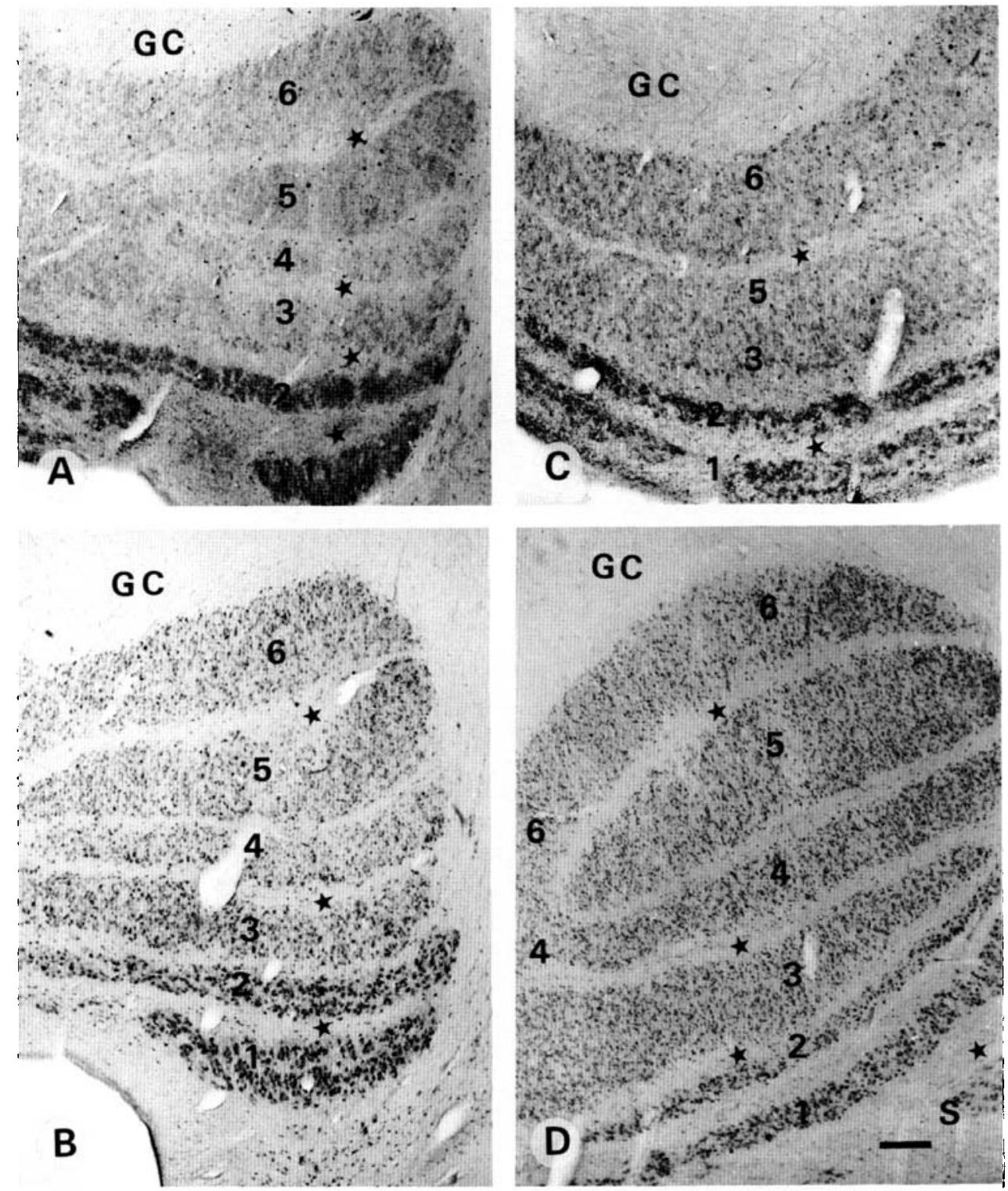

Fig. 2. Light micrographs demonstrating CR-ir (A,C) and CB-ir (B,D) in the human LGN. (A) case 1 (see Table 1); (B) case 1; (C) case 6; and (D) case 3. Note that in (A) and (C) the CR-ir is higher in the $M(1$ and 2$)$ than in the $P(3-6)$ laminae, whereas, in (B) and (D) the difference between the CB-ir M and P laminae is not as striking. GC: geniculate capsule, and $\left(^{*}\right)$ interlaminar zones. $S$ represents a part of the ventral-most lamina which is also CB-ir. Scale bar in $A-D=500 \mu \mathrm{m}$.

and fibers running roughly parallel to each other were also present (Figs. 4C and 4D). CB-ir neurons were less strongly marked. As in the LGN, there were neither fibers nor puncta which were $\mathrm{CB}$-ir. In the pulvinar capsule, we observed both PV-ir puncta and CR-ir fibers (Fig. 4), but CB-ir fibers or puncta were rare.

\section{Primary visual cortex and underlying white matter}

(Figs. 5-7; Table 2)

Primary area 17 showed a stronger PV immunoreactivity in the recipient layer IV than in layers II-III and V-VI (Figs. 5A and 5C). This was mainly due to a high density of puncta, representing transversally cut axons and dendrites (see Discussion), as well as to numerous PV-ir neurons (Figs. 5C and 5D), most of which resembled small granule cells with multipolar dendritic arborization. In other layers PV-ir neurons resembled either chandelier or basket types. In the white matter, PV-ir fibers ran parallel to the cortical layers and were confined mostly to the region underlying layer VI of area 17 (Figs. 5A-5C and 5E). In the white matter underlying layer VI of area 18 , such dense fibers were not observed (Figs. 5A-5C). A few PV-ir interstitial neurons, mostly of bipolar shape with long dendrites oriented parallel to the fibers, were encountered in the white matter (Figs. 5F and 5G). The pattern of $\mathrm{CR}$ immunoreactivity was completely different. A high density of puncta, together with numerous $C R$-ir neurons, was observed in the superficial layers I and II (Figs. 6A and 6B). On the surface of layer I, a few CR-ir Cajal-Retzius neurons, showing a cell body and dendritic arborization oriented parallel to the pial surface, were encountered (Figs. 6B and 6C). In layers II-IV, most CR-ir neurons showed a bipolar or bitufted dendritic arbor oriented perpen- 

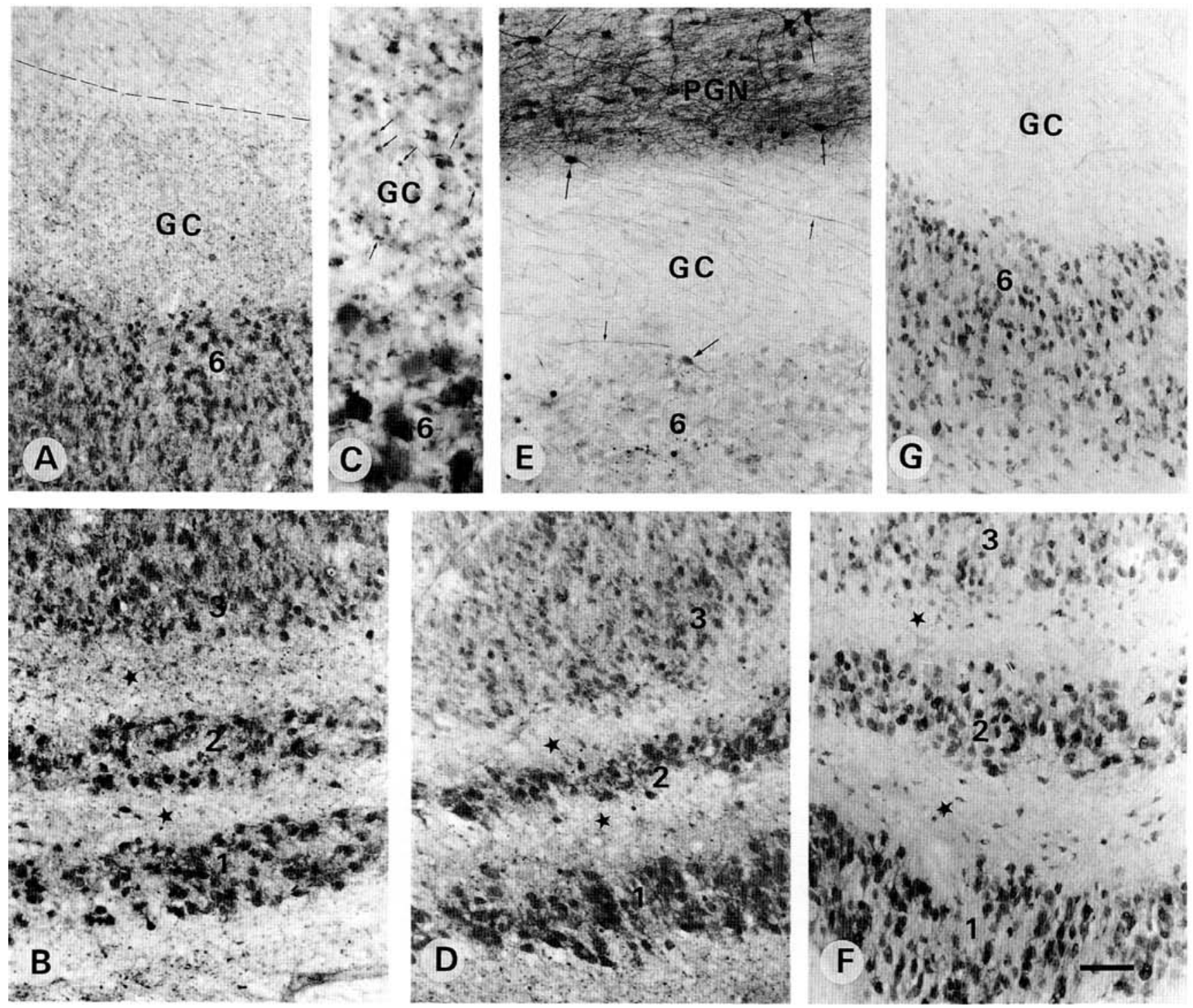

Fig. 3. (A-C) Photomicrographs showing the presence of numerous PV-ir puncta in the geniculate capsule (GC) and the interlaminar zones $\left(^{*}\right)$. Such puncta (arrows) are better seen at a higher magnification in (C). (D) shows CR-ir puncta in the interlaminar zones (*). (E) shows numerous CR-ir fibers (small arrows) in the geniculate capsule (GC). Note that the CR-ir neurons (big arrows) are better marked in the pregeniculate nucleus (PGN) than those in lamina 6 of the LGN. (F) and (G) show hardly any $\mathrm{CB}$-ir fibers and/or puncta in the geniculate capsule $(\mathrm{GC})$ and interlaminar zones ${ }^{*}$ ). In (F), a few scattered CB-ir neurons are also present within the interlaminar zones $\left(^{*}\right)$. Scale bar in $A, B, D, E, F$, and $\mathrm{G}=100 \mu \mathrm{m} ; \mathrm{C}=50 \mu \mathrm{m}$.

dicular to the cortical layers, while others showed a small multipolar arborization. In layer $\mathrm{V}$, the density of $\mathrm{CR}$-ir puncta was as strong as in layers I-II and a few CR-ir neurons of multipolar and sometimes pyramidal shape were also encountered (Fig. 5F). In the deepest layer VI, a few CR-ir multipolar neurons were also observed (Fig. 6D). In the white matter, numerous $C R$-ir fibers running parallel to each other were present below layer VI of area 17 but not 18 . Widely scattered CR-ir interstitial neurons of bipolar and multipolar types including the pyramidal shape (Fig. $6 \mathrm{E}$ ) were observed with their dendritic arborization oriented either parallel or perpendicular to the fibers (Fig. 6E). The pattern of $\mathrm{CB}$ immunoreactivity was also very clear (Fig. 7). CB-ir neurons were confined mainly to layer II, less to layer III, and very few to the deeper layers. They showed a clear and intensely immunoreactive dendritic arborization mostly of double bouquet or multipolar shape (Figs. 7A-7D). The ascending dendrites contributed to the density of puncta which was highest in the superficial layer I (Figs. 7A-7D). CB-ir fibers and neurons in the white matter were rare (Figs. 7A and 7E).

\section{Superior colliculus (Figs. 8-9; Table 2)}

In the SC, PV-ir neurons were widely scattered throughout its depth (Fig. 8A). They included small- to large-size neurons ranging between $8-25 \mu \mathrm{m}$ in their maximum diameter, mostly multipolar, pyramidal-like and a few bipolar in shape. Stratum griseum superficiale (SGS) showed lightly labelled PV-ir puncta mainly in its upper part, below which small-size neurons mostly of multipolar shape were encountered. Stratum griseum inter- 
Table 2. Distribution of immunoreactivity for parvalbumin $(P V)$, calretinin $(C R)$, and calbindin $(C B)$ in different structures of the human visual system ${ }^{a}$

\begin{tabular}{|c|c|c|c|c|c|c|}
\hline & \multicolumn{3}{|c|}{ Neurons } & \multicolumn{3}{|c|}{ Fibers and/or puncta } \\
\hline & PV & CR & $\mathrm{CB}$ & PV & CR & $\mathrm{CB}$ \\
\hline LGN P & + & + & + & + & + & - \\
\hline LGN M & + & ++ & $+(+)$ & + & + & - \\
\hline LGN ILZ & $-(+)$ & $-(+)$ & $-(+)$ & + & + & - \\
\hline LGN capsule & + & + & - & + & + & - \\
\hline PG nucleus & ++ & ++ & $+(-)$ & + & + & - \\
\hline LIP & + & + & + & + & + & - \\
\hline OR & + & + & $-(+)$ & $+(+)$ & $+(+)$ & $-(+)$ \\
\hline SC SGS & + & $+(+)$ & $+(-)$ & $+(+)$ & $+(+)$ & $+(t)$ \\
\hline SC SGI & + & $+(+)$ & $+(-)$ & + & + & $+(t)$ \\
\hline SC SGP & + & $+(+)$ & $+(-)$ & + & + & + \\
\hline A17 GM & $+t$ & $+t$ & + & ++ & ++ & $+(t)$ \\
\hline A17 WM & ++ & $+t$ & - & ++ & ++ & $-(+)$ \\
\hline
\end{tabular}

${ }^{\mathrm{a}} \mathrm{LGN}$ : lateral geniculate nucleus; P: parvocellular laminae; $\mathrm{M}$ : magnocellular laminae; ILZ: interlaminar zones; PG: pregeniculate nucleus; LIP: lateral inferior pulvinar; OR: optic radiation; SC: superior colliculus; SGS: stratum griseum superficiale; SGI: stratum griseum intermedium; SGP: stratum griseum profundum; A17: area 17; GM: grey matter; and WM: white matter. The intensity of the immunoreactivity was appreciated as strong ++ medium + or absent - ; intermediate situations were not uncommon $(+),(-)$.

medium (SGI) showed a relatively higher density of neurons most of which were of medium to large size. A few small bipolar cells oriented perpendicular to the pial surface were also encountered. Stratum griseum profundum (SGP) demonstrated a mixed population of small- to medium-size neurons. A few large immunoreactive neurons (Fig. 8A, inset) in the upper and lower part of the SGP were also observed. CB-ir neurons were weakly stained and more widely scattered (Fig. 8B) as compared to the PV-ir ones. However, the puncta were more intensely stained and showed a highest density (Fig. 8B) just below the stratum zonale (SZ). SGS showed only a few widely scattered neurons of small size. In SGI, many large neurons together with a few small- to medium-size cell bodies were observed. SGP showed as widely scattered a population of neurons as the SGS but the neurons were of medium to large size. CR-ir neurons appeared to be more numerous than $\mathrm{PV}$-ir or CB-ir neurons throughout the SC (Fig. 9). Even in the stratum zonale a few small immunoreactive neurons were observed (Fig. 9A, inset). Stratum griseum superficiale showed immunoreactive neurons of small- to medium-size mainly in its lower half. The upper half of SGS revealed a high density of puncta. SGI revealed a broad band of immunoreactive, small- to large-size neurons. Several showed a pyramidal-shaped cell body with a thick proximal dendrite oriented towards the pial surface (Fig. 9B and inset). Small- to medium-size neurons were multipolar and bipolar in shape. SGP showed a mixed population of a few large and many small- to medium-size neurons of mostly multipolar and some pyramidal-like in shape.

\section{Discussion}

In primates, visual information is processed along two main parallel visual pathways, referred to as magnocellular (M) and parvocellular (P) pathways, carrying specific clues relative to the perception of motion (M) or color and form (P) (Livingstone \& Hubel, 1988). However, a third visual pathway which seems to play a role in the integration of visual information has been described as anatomically, neurophysiologically, and neurochemically distinct - the koniocellular $(\mathrm{K})$ pathway (Casagrande, 1994; Johnson \& Casagrande, 1995). Indeed, in prosimian monkeys such as Galago crassicaudatus, the LGN has six laminae, two of which -4 and 5 , koniocellular - have smaller relay cells which stain specifically for calbindin, while there is a complementary pattern of staining for parvalbumin in the other $\mathrm{M}$ and P laminae (Diamond et al., 1993; Casagrande, 1994; Johnson \& Casagrande, 1995). In simian monkeys, such as Macaqua mulatta or fascicularis, the koniocellular laminae correspond mostly to the interlaminar zones (ILZ) and S laminae, while the remaining laminae 1 and 2 are magnocellular and laminae 3-6 are parvocellular. The projection from the SC to the LGN, which reaches the $\mathrm{K}$ laminae in prosimians (Lachica \& Casagrande, 1993), seems to reach mainly the ILZ in simians (Casagrande \& Norton, 1991). In simians, the complementary pattern of PV and CB staining is found respectively in $M$ and $P$ laminae on the one hand, and in the ILZ and $S$ laminae on the other hand, although there is some PV staining in ILZ and S laminae as well (Jones \& Hendry, 1989). CR staining has not been described in primate LGN. Our data in human bring some new information about common and different features between primate species.

$\mathrm{PV}$ immunoreactivity is found in all two $\mathrm{M}$ and four $\mathrm{P}$ laminae of the human LGN, with a high proportion of immunoreactive neurons. Since most neurons are marked, including the larger ones with a clear multipolar shape, this indicates that they likely represent projection neurons rather than interneurons which are only $8 \%$ in the human LGN (Braak \& Bachmann, 1985). As LGN neurons project almost exclusively to the primary visual area in primates (Casagrande \& Norton, 1991), the dense plexus of PV-ir puncta in the geniculate capsule and optic radiation probably represents transversally cut axons. Indeed, immunoreactive puncta have been described as corresponding to axonal and dendritic terminals by several authors (Stichel et al., 1988; Blümcke et al., 1991; Fonseca et al., 1993). In the white matter underlying area 17, PV-ir fibers stop at the limit with area 18 , turning often perpendicularly toward the cortical layers, where dense PV-ir puncta are observed in the thalamorecipient layer IV. In Macaque monkey where similar PV-ir puncta have been observed, the presence of a high number of PV-ir asymmetric contacts in layer IV of area 17 suggested that they were derived from the axons of the LGN PV-ir neurons (Blümcke et al., 1991; DeFelipe \& Jones, 1991). A recent study in Galago, combining cell-size analysis, retrograde and double labelling, demonstrated that PV-ir LGN neurons project to layer IV and III of area 17 (Johnson \& Casagrande, 1995). Our data provide only indirect evidence of $\mathrm{PV}$-ir projections from $M$ and $P$ LGN laminae to primary area 17 in human but comparison with other simians makes it reasonable. Moreover, PV-ir neurons in interlaminar zones were almost absent in humans, as in Macaque monkeys (Jones \& Hendry, 1989).

However, we did not find a complementary pattern of $C B$ immunoreactivity in the LGN interlaminar zones as described in other simians (Jones \& Hendry, 1989), but on the contrary, a very well-marked population of $\mathrm{CB}$-ir neurons in all laminae of the LGN, with a slightly denser staining in the M laminae and scattered neurons in the ILZ. Questions about the antibody specificity in human may be addressed, but the specificity of 

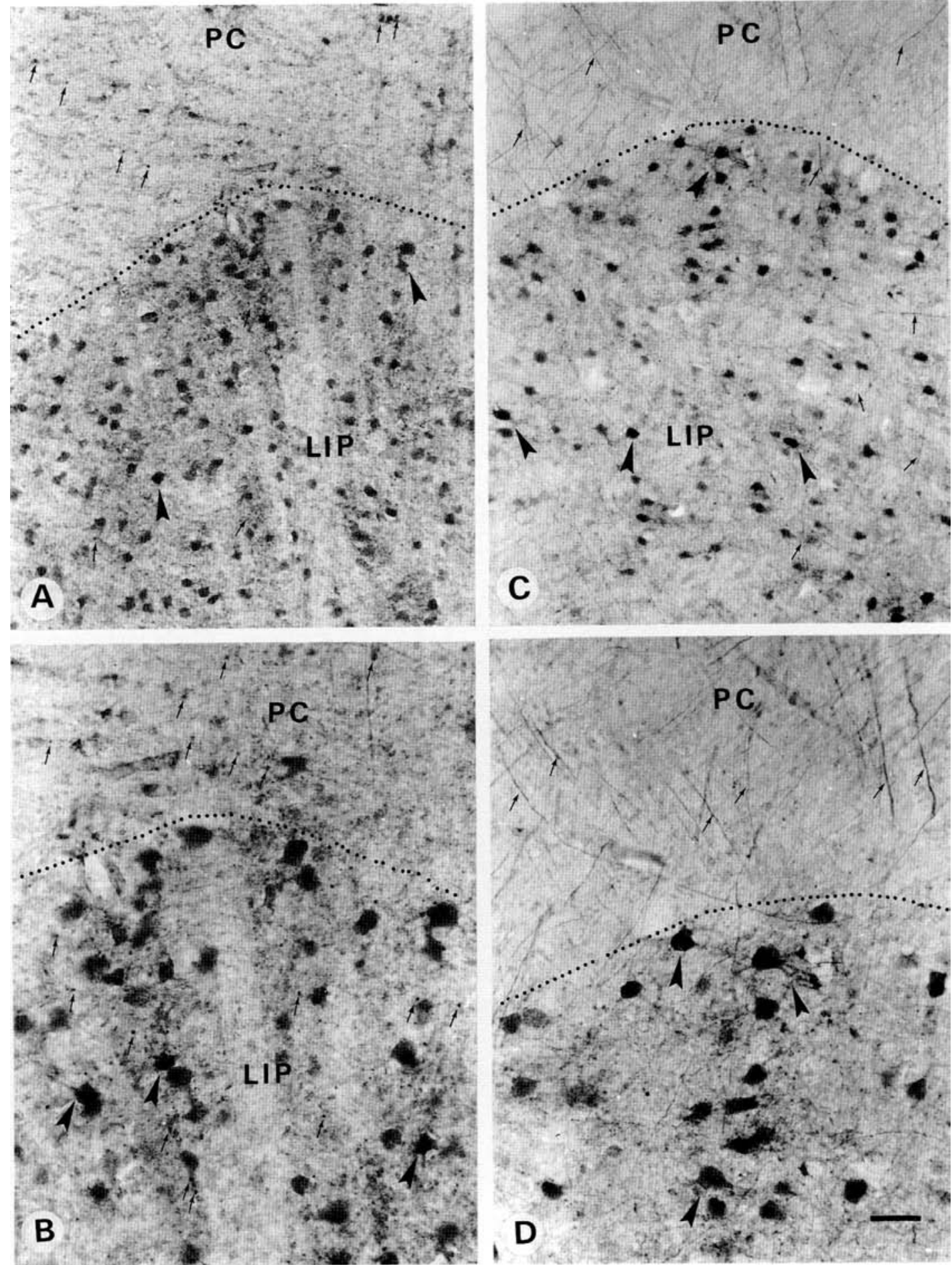

Fig. 4. Photomicrographs demonstrating $P V(A, B)$ and $C R(C, D)$ immunolabeling in the lateral inferior pulvinar (LIP). (A,B) Note the presence of PV-ir neurons (arrowheads) in LIP. PV-ir puncta (arrows) are seen in LIP as well as in the pulvinar capsule (PC). (C,D) Note the presence of CR-ir neurons (arrowheads) and fibers (arrows) in LIP as well as in the capsule (PC). Scale bar in $A, C=75 \mu \mathrm{m} ; \mathrm{B}, \mathrm{D}=40 \mu \mathrm{m}$.

our Celio monoclonal antibody against calbindin-D28K is well known and in area 17 of the same cases, it works remarkably well, marking only specific populations of interneurons with a defined morphology. Furthermore, it has been used in other human cortical regions with the same success (Tunon et al., 1992). Puncta in layers I-III of area 17 are CB-ir, but neither puncta nor fibers are positive along the geniculo-cortical pathway. In Macaque monkey, CB immunoreactivity has been described as very light and $\mathrm{PV}$ immunoreactivity as particularly strong in the optic tract (Jones \& Hendry, 1989). It may happen that only the thalamic perikarya and their cortical terminals are stained while the intervening axons remain negative; 


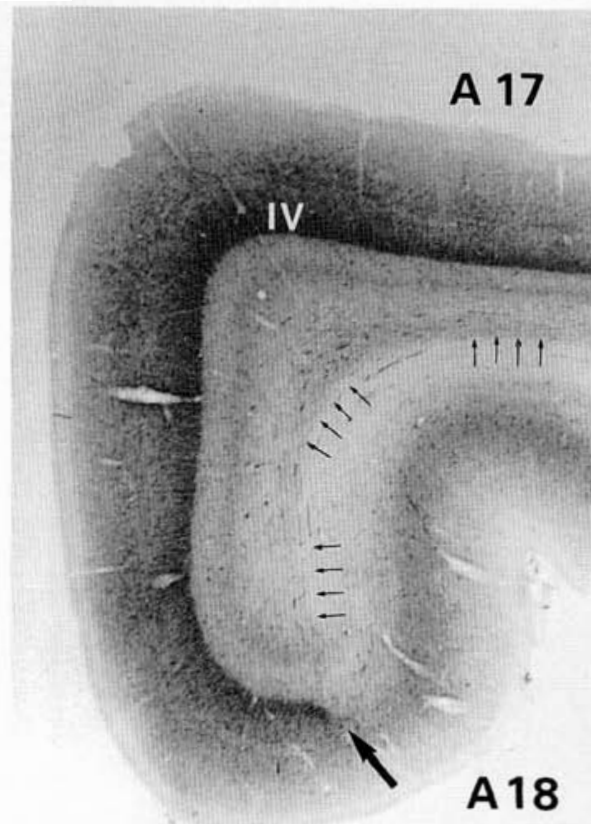

A

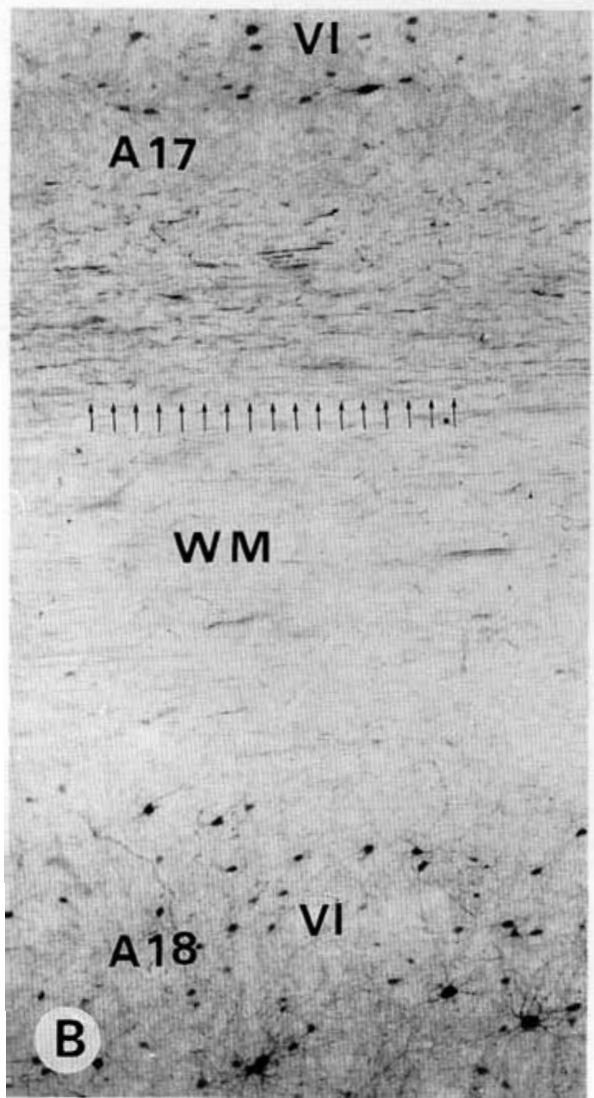

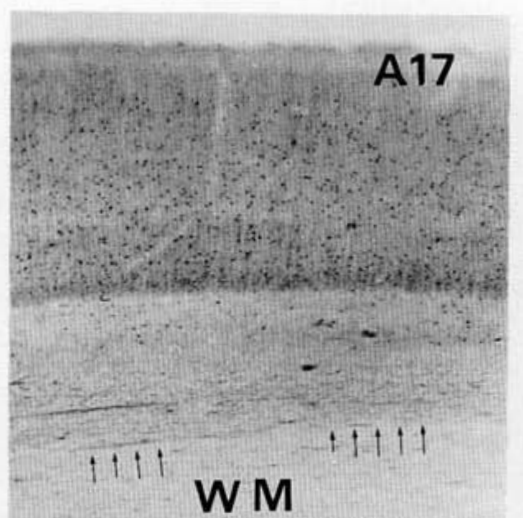
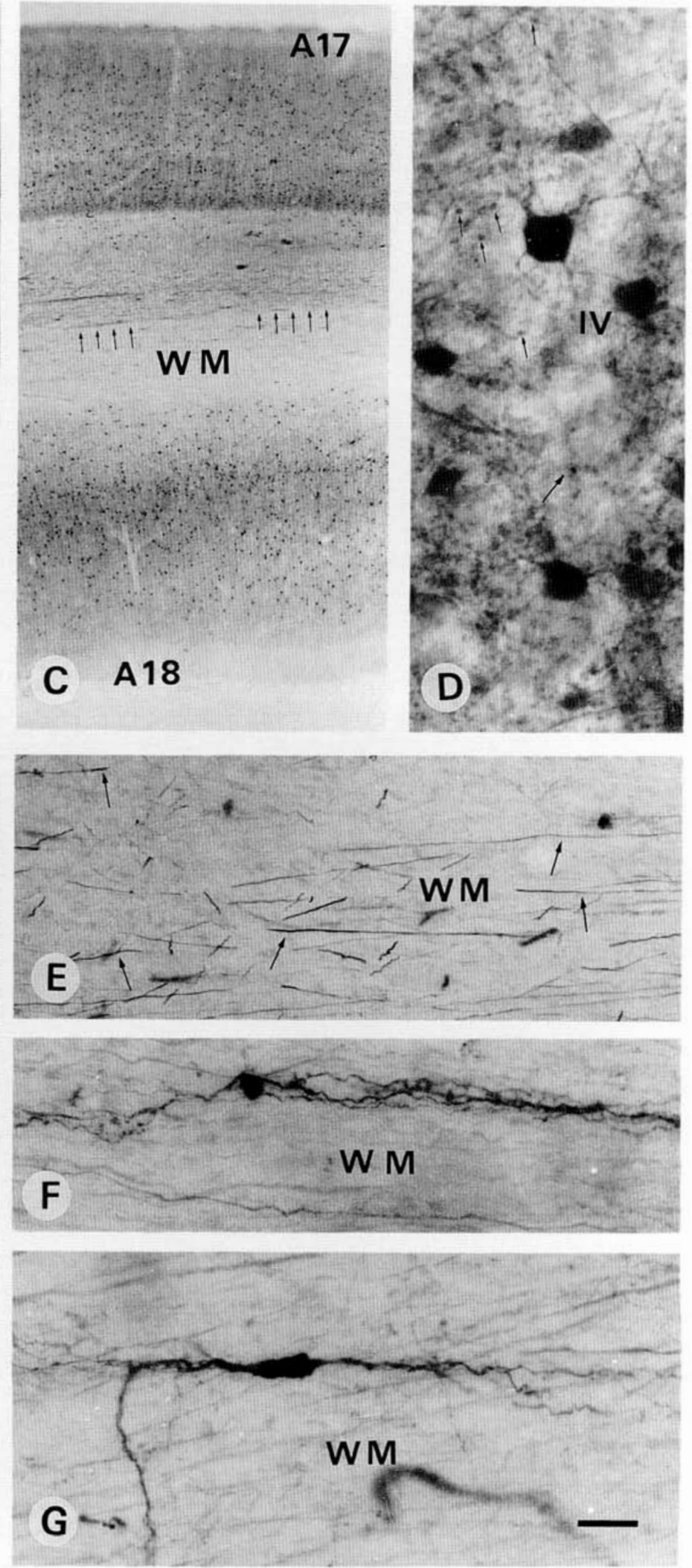

Fig. 5. Photomicrographs demonstrating PV-ir neurons and fibers in the primary visual area 17 . $(A, C)$ Note that the thalamocortical recipient layer IV is strongly immunoreactive. PV-ir neurons are more numerous in layers III and IV than in layers II, V, and VI. Layer I is totally devoid of PV immunoreactivity. The white matter (WM) underlying layer VI shows a bundle of PV-ir fibers (small arrows) which extends to the limit between area 17 and 18. (B) A higher magnification of the PV-ir fibers underlying layer VI of area 17 but not of area 18. (D) shows PV-ir puncta (arrows) and multipolar neurons in layer IV at a high magnification. (E-G) show at a high magnification the PV-ir fibers and neurons oriented parallel to the fibers in the white matter (WM) underlying area 17. Scale bar in $A=1 \mathrm{~mm} ; \mathrm{B}=100 \mu \mathrm{m} ; \mathrm{C}=750 \mu \mathrm{m} ; \mathrm{D}=25 \mu \mathrm{m} ; \mathrm{E}-\mathrm{G}=40 \mu \mathrm{m}$. 


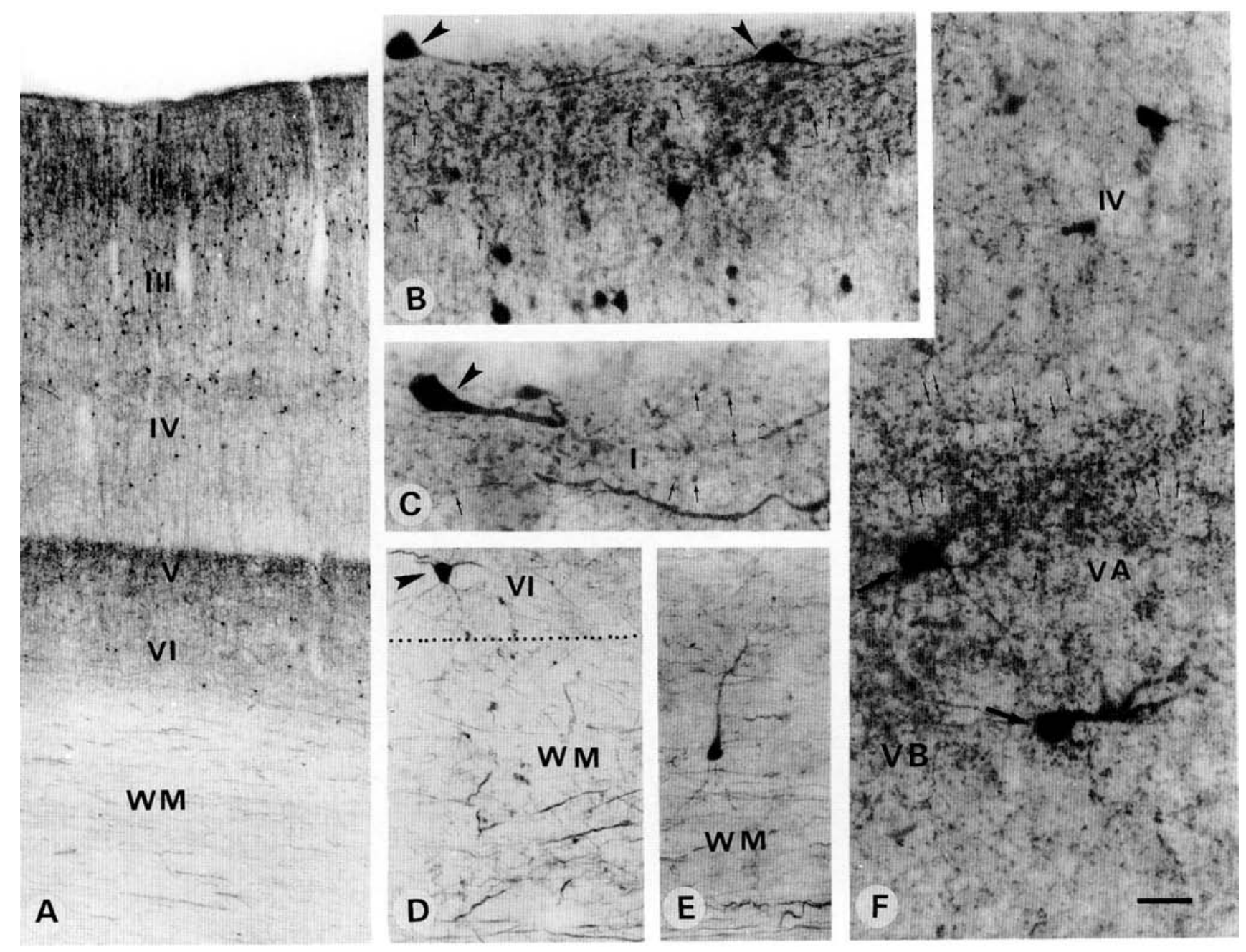

Fig. 6. Light micrographs demonstrating $C R$-ir neurons and puncta in the primary visual area 17. (A) CR-ir neurons are seen mainly in the superficial layers (II-III), whereas, in the deep layers (IV-VI) they are sparse and widely scattered. CR immunoreactivity in the neuropil of layer $V$ is as strong as in layers I and II. (B,C) At a higher magnification, layer I shows densely stained CR-ir puncta (arrows) as well as Cajal-Retzius cells (arrowheads) oriented parallel to the pial surface. (D) Several CR-ir fibers (arrows) of different size, as well as scattered neurons (E) are present in the white matter (WM) underlying the deep layer VI. (F) A higher magnification of layer $\mathrm{V}$ reveals the density of immunoreactive puncta (big arrows) concentrated mainly in its upper part, layer VA and a few large multipolar immunoreactive neurons. Scale bar in $A=250 \mu \mathrm{m} ; B, D=40 \mu \mathrm{m}$; $\mathrm{C}, \mathrm{E}=25 \mu \mathrm{m}$.

this intracellular segregation of immunoreactivity has been observed in various instances (M.R. Celio, personal communication). Thus, a nonspecific projection from the CB-ir LGN neurons to superficial layers of primary area 17 is quite feasible in human. It would however originate in all LGN laminae, contrary to the other primate's pattern where only the smallest laminar and interlaminar cells, as well as neurons of the S laminae, appear to send projections to the superficial visual layers (Casagrande \& Norton, 1991; Johnson \& Casagrande, 1995). In only a few cases, we could see one of the $S$ laminae, and when present it was CB positive. Such CB-ir projections from the koniocellular laminae of the LGN to the superficial layers of the visual cortex were demonstrated recently in the prosimian Galago (Johnson \& Casagrande, 1995) as well as in Macaque monkey, from the medial geniculate nucleus to layer I of the cerebral cortex (Hashikawa et al., 1991). Because calcium-binding immunostaining combined with either retrograde-labeling
(Johnson \& Casagrande, 1995) or fluorescent tracer (Hashikawa et al., 1991) experiments is not possible in human, additional information should be obtained by double labeling and quantitative distribution of PV-ir and CB-ir neurons (study in progress).

CR-ir neurons have not been described in the primate LGN, but our data demonstrate immunoreactive neurons and fibers in all laminae, with a more intense staining in the $M$ laminae and only rare neurons in the ILZ. The presence of fibers in the geniculate capsule, optic radiation, and underlying white matter of area 17 suggests that there are CR-positive visual thalamic projections in human. Within area 17 , there are two dense zones of CR-ir puncta, one at the level of superficial layers I and II and the other at the level of layer V. Although puncta represent largely the terminals of cortical interneurons, they may represent partly the terminals of subcortical afferents, as it was shown for PV in monkeys (Blümcke et al., 1991; DeFelipe \& 


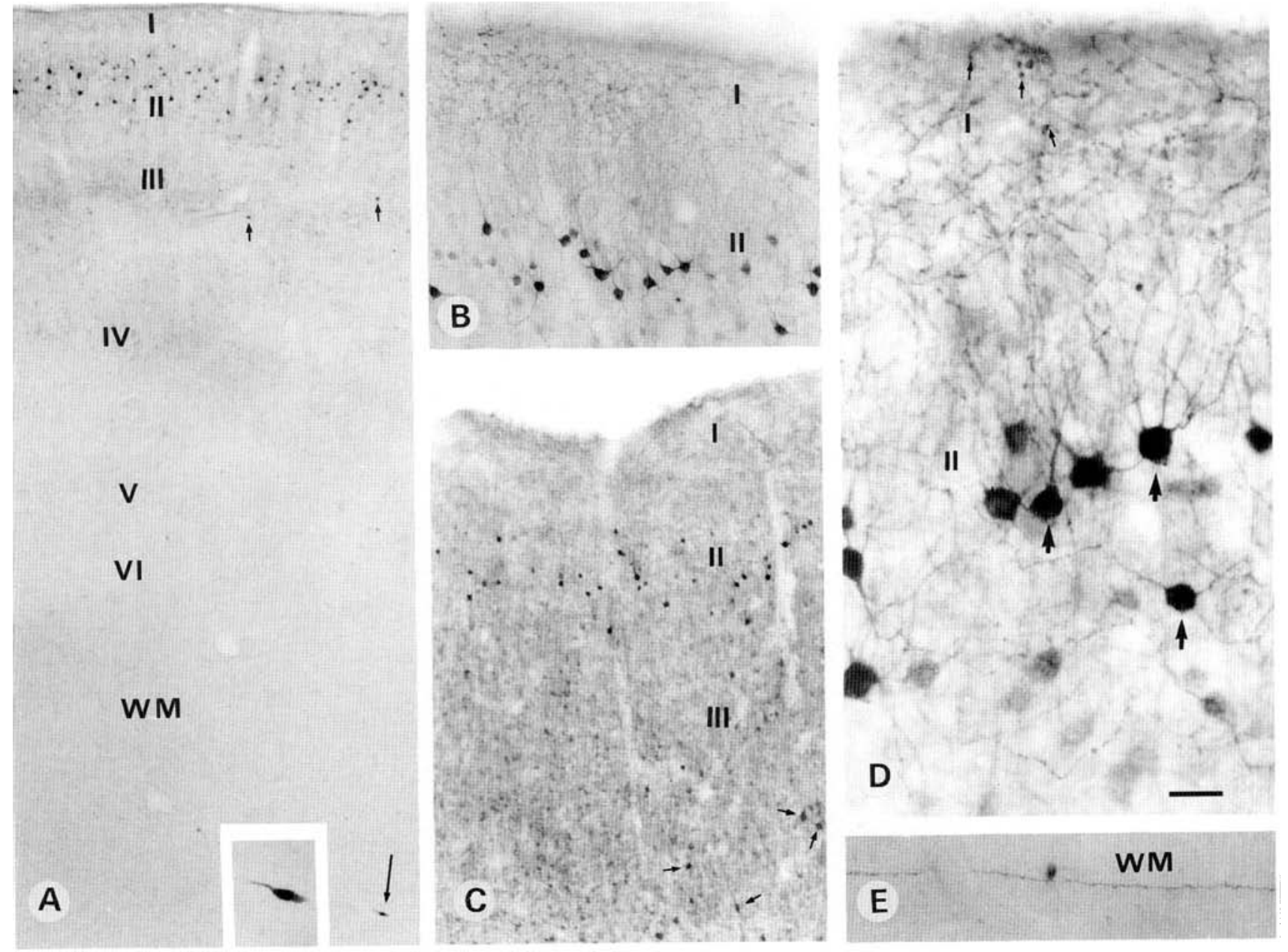

Fig. 7. Light photomicrographs demonstrating CB-ir neurons and puncta in the primary visual area 17. (A, C) CB-ir neurons are confined mainly to the superficial layers II and III, whereas, the deep layers IV-VI are relatively free of immunoreactive neurons. Arrow in the white matter (WM) indicates a very rare CB-ir neuron, enlarged in the inset. (B, D) show layer II CB-ir neurons whose ascending dendrites contribute to the puncta seen in layer I. (E) A rare CB-ir white matter neuron. Scale bar in $\mathrm{A}=250 \mu \mathrm{m} ; \mathrm{B}=75 \mu \mathrm{m} ; \mathrm{C}=150 \mu \mathrm{m} ; \mathrm{D}=25 \mu \mathrm{m} ; \mathrm{E}=50 \mu \mathrm{m}$.

Jones, 1991; Johnson \& Casagrande, 1995). As there are no comparative $\mathrm{CR}$ data in primates, we can only suggest that CRpositive LGN projections could reach specific layers of area 17. However, the distribution of CR-ir cortical interneurons matches completely with that already described (Glezer et al., 1992) and the presence of Cajal-Retzius CR-ir neurons in layer I of area 17 is in accordance with recent observations in humans (Belichenko et al., 1995).

In the optic radiation and in the white matter underlying area 17, PV-ir and more particularly CR-ir neurons are also present. Their morphology is clearly neuronal, with long dendrites parallel or perpendicular to the fibers, and our preliminary observations, combining calcium-binding proteins with GFAP immunostaining, have shown that they were not glial cells. The role of these white matter neurons is still unclear but seems to be essential in development for the final target selection of thalamic axons to the cortical recipient layers (Ghosh \& Shatz, 1992). In close vicinity to the $\mathrm{LGN}$, the pregeniculate nucleus receives also direct retinal afferents and seems to be the homologue of the rodent intergeniculate leaflet playing a role in the organization of the primate circadian system (Moore, 1993). It projects to different subcortical structures, including the LGN itself, the suprachiasmatic nucleus (Moore, 1993), the nucleus of the optic tract (Mustari et al., 1994), and seems reciprocally connected with the visual association cortex and temporal area MT (Maioli et al., 1984; Leichnetz, 1990). The few large PV-ir and $\mathrm{CR}$-ir neurons probably represent projection neurons already described in the monkey pregeniculate nucleus (Jones \& Hendry, 1989).

In the pulvinar capsule, PV-ir puncta and CR-ir fibers seem to be axons from the PV-ir and CR-ir neurons, which will partly join the optic radiation and contribute to the immunoreactive fiber bundles of the white matter underlying area 17 . However, primate cortical projections originating in the pulvinar not only reach the primary visual cortex, but also several temporal, parietal, and orbito-frontal visually related areas (Morecraft et al., 1992; Baizer et al., 1993). From the pattern of connections, it was inferred that the PV-ir perikarya, particularly rich in the medial division of the pulvinar, were mainly the fast-firing neurons projecting to area MT (Cusick et al., 1993).

Finally, in the three grey laminae of the SC, the PV-ir and $\mathrm{CR}$-ir neurons are mostly of medium to large size, which may 

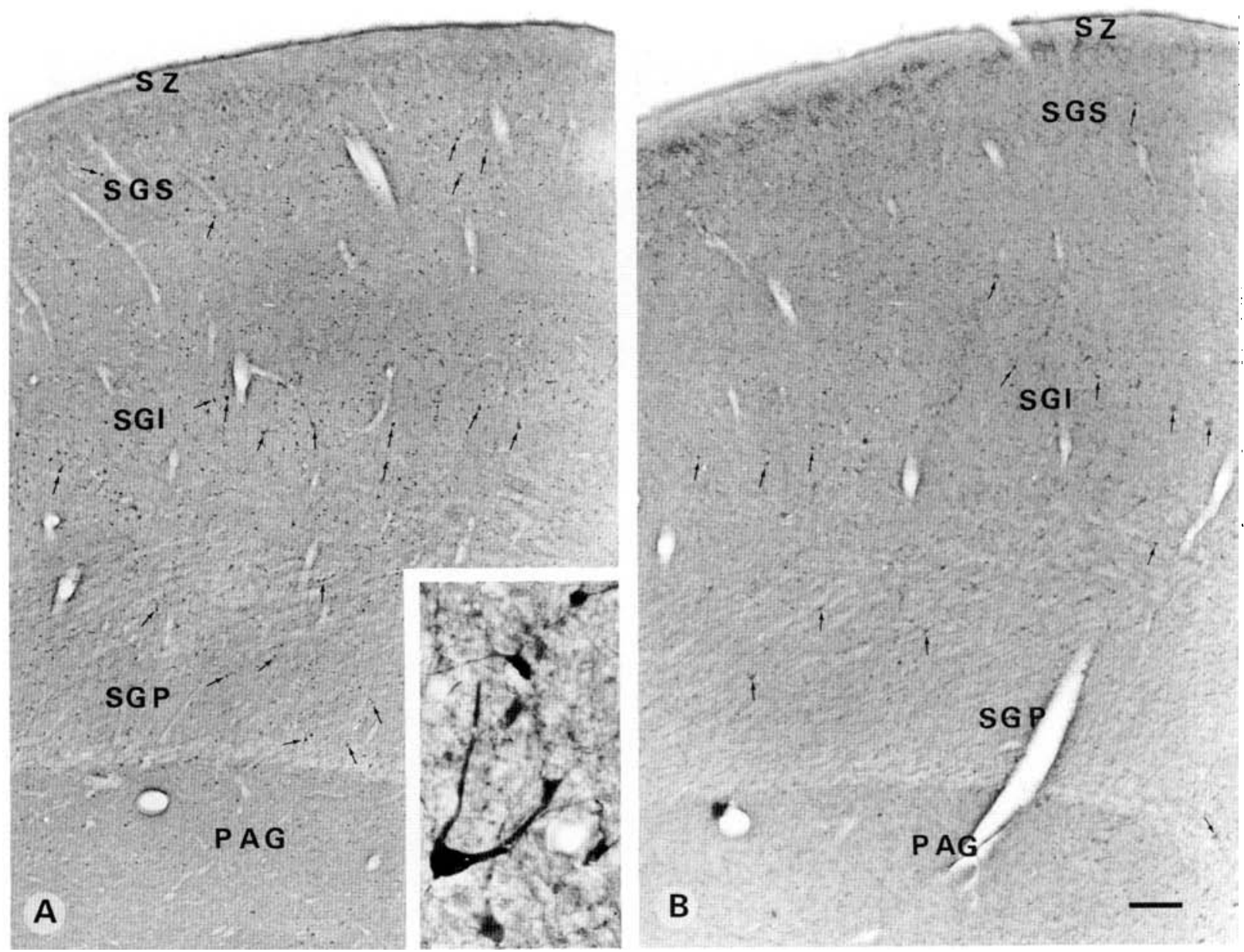

Fig. 8. Light photomicrographs demonstrating PV (A) and CB (B) immunostaining in the superior colliculus. (A) Note that PV-ir neurons (arrows) are widely scattered in all the layers. They show a slightly greater concentration in the stratum griseum intermedium (SGI) and include small- to large-size neurons of multipolar and pyramidal-like shape (Inset). Lightly stained PV-ir puncta show a greater density in the upper part of the stratum griseum superficiale (SGS). (B) CB-ir neurons (arrows) are more widely scattered and not as strongly marked as the PV-ir ones. They include also small- to large-size neurons of multipolar and pyramidal-like shape. Intensely stained CB-ir puncta concentrate in the upper part of the SGS. Stratum zonale (SZ) is free of immunoreactive neurons. Scale bar in $A, B=350 \mu \mathrm{m}$; inset $=30 \mu \mathrm{m}$.

project outside the nucleus towards the pontine nuclei and the medulla or towards the LGN (Stein \& Meredith, 1993). Smaller neurons are less immunoreactive and may include both projection neurons and interneurons. However, neurons making a local axonal arborization are rare in the primate SC (Ma et al., 1990 ). In the cat SC, about $84 \%$ of the projection neurons identified by horseradish peroxidase injections in several visually related structures such as the $\mathrm{LGN}$, the lateral posterior nucleus, the opposite SC, or descending tectal pathways are PV-positive, while the CB-ir neurons are smaller and identified as interneurons (Mize et al., 1992a). This characteristic complementary distribution of PV-ir and CB-ir neurons was not observed in human, where CB-ir neurons are widely scattered throughout the nucleus, but until now there are no comparative data in primates.

The reason why calcium-binding proteins are expressed mainly by interneurons in the cerebral cortex and projection neurons in subcortical structures is unknown and their distribution is also largely species dependent (Baimbridge et al., 1992). Our data bring some more information on these species differences in the visual system. In primates, these differences appear to be more prevalent in subcortical than in cortical structures. The primary effect of these proteins involves mainly the promotion and maintenance of neuronal activity by controlling the entrance of calcium into the cell, and thus a series of intracellular signals; but it could include as well the regulation of cytoskeletal organization, cell motility and differentiation, fast axonal transport, and synthesis and release of some neurotransmitters (Baimbridge et al., 1992; Heizmann, 1992, 1993). The colocalization of PV with Cat-301 (Rausell \& Jones, 1991) suggested a higher calcium-buffering requirement for the fast-firing neurons of the magnocellular pathway (Mize \& Hockfield, 1989; Hockfield \& Sur, 1990; Hockfield et al., 1990). It has also been suggested that interneurons containing calcium-binding proteins would be more resistant to degeneration (Heizmann, 1992, 1993; Eckert et al., 1994), but data in this domain are conflicting, at least in the human (Heizmann \& Braun, 1992). In monkeys, experiments of visual deprivation fail to reduce CB immuno- 

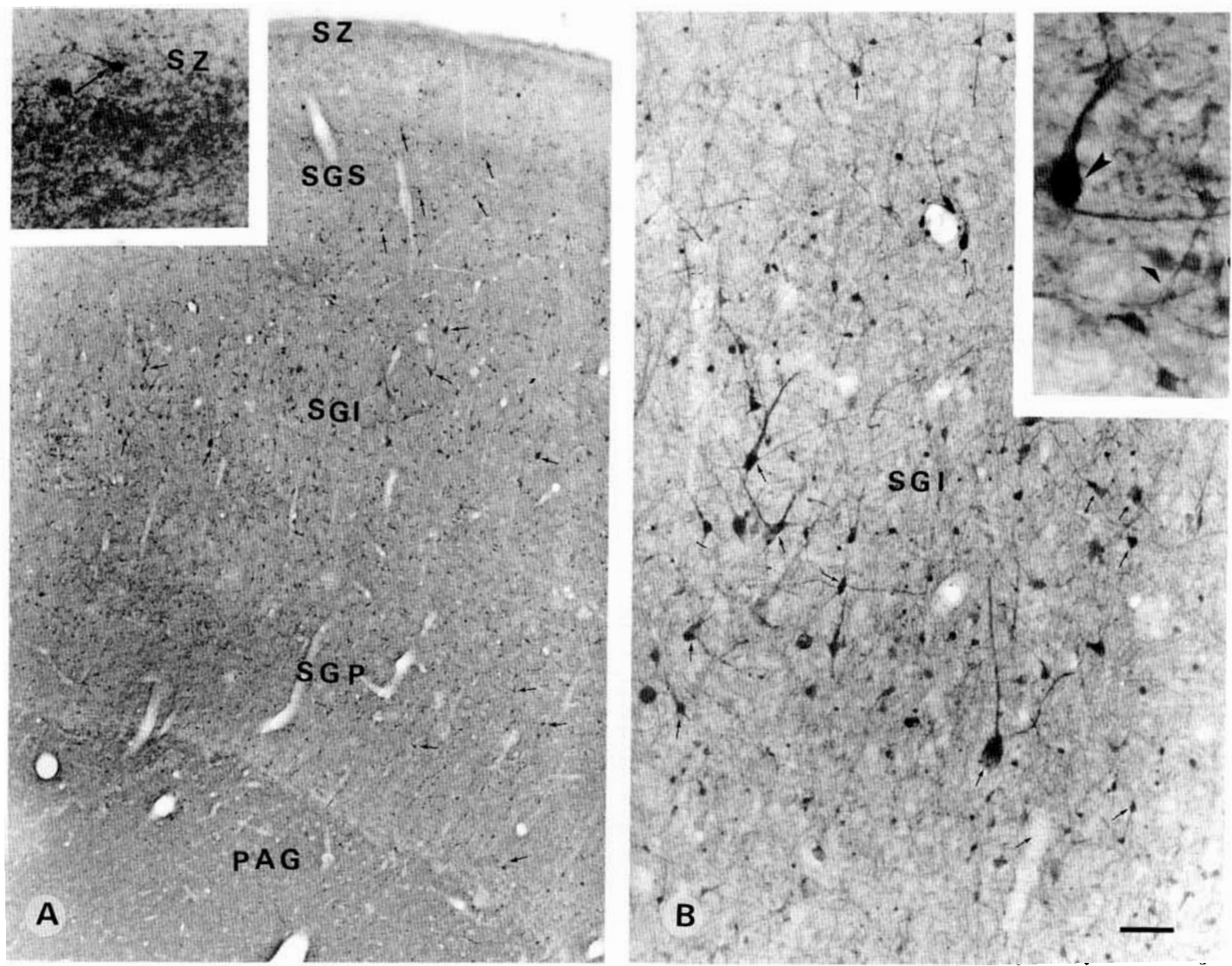

Fig. 9. Light photomicrographs demonstrating CR immunostaining in the superior colliculus. (A) CR-ir neurons (arrows) are widely scattered but more numerous in the stratum griseum intermedium (SGI). They include many large neurons of multipolar and pyramidal-shaped cell bodies among which smaller neurons of different size are also marked. (A, inset) Arrow indicates a small CR-ir neuron in the stratum zonale (SZ) and the region below it shows a high density of puncta in the most upper part of the SGS. (B) shows a higher magnification of CR-ir neurons in SGI. Inset shows a large neuron (long arrowhead) and a few smaller neurons (small arrowhead) Scale bar in $A, B=350 \mu \mathrm{m}$; inset $=30 \mu \mathrm{m}$.

reactivity in the SC (Mize \& Luo, 1992) or PV immunoreactivity in the LGN (Tigges \& Tigges, 1993), but deafferentation produces a discrete reduction of $\mathrm{CB}$ immunoreactivity in the LGN (Mize et al., 1992b) as well as of PV immunoreactivity in the LGN and visual cortex (Blümcke et al., 1994). However, when neurons still express calcium-binding proteins in these experimental conditions, a shift in the expression of $P V$ and $C B$ may occur, for instance coexpression of both $\mathrm{PV}$ and $\mathrm{CB}$ in response to neuronal injury (Gutierrez \& Cusick, 1994).

Although it is not yet possible to make a precise link between transmitter and neuronal type on the one hand and a PV, CR, or $\mathrm{CB}$ content on the other hand, the calcium-binding protein profile in the human visual system seems to present both similarities and differences with other primates. The functional distinctiveness of these different neuronal populations remains to be explored in greater detail.

\section{Acknowledgments}

This study was supported by the Swiss National Science Foundation (No. 3100-034491.92 and 3100-043573.95). We thank Professor J. Wert- heimer for his great encouragement and support; Professor L.J. Garey and Professor M.R. Celio for critical review of the manuscript; Professor M.R. Celio for donating the antibodies; Professor R.C. Janzer, Dr. J. Miklossy (Lausanne), and Professor J. Ulrich (Basel) for providing autopsy material; and C. Dumas for technical assistance.

\section{References}

Aral, M., Aral, R., KanI, K. \& Jacobowitz, D.M. (1992). Immunohistochemical localization of calretinin in the rat lateral geniculate nucleus and its retino-geniculate projection. Brain Research 596, 215-222.

Baimbridge, K.G., Celio, M.R. \& Rogers, J.H. (1992). Calciumbinding proteins in the nervous system. Trends in Neurosciences 15 , 303-308.

Baizer, J.S., Desimone, R. \& Ungerleider, L.G. (1993). Comparison of subcortical connections of inferior temporal and posterior parietal cortex in monkeys. Visual Neuroscience 10, 59-72.

Belichenko, P.V., Vogt Weisenhorn, D.M., Myklossy, J. \& Celio, M.R. (1995). Calretinin-positive Cajal-Retzius cells persist in the adult human neocortex. Neuroreport 6, 1869-1874.

BlüMCKe, I., Hof, P.R., Morrison, J.H. \& Celio, M.R. (1990). Distribution of parvalbumin immunoreactivity in the visual cortex of 
old world monkeys and humans. Journal of Comparative Neurology 301, 417-432.

BlúmCKe, 1., Hof, P.R., Morrison, J.H. \& Celio, M.R. (1991). Parvalbumin in the monkey striate cortex: A quantitative immunoelectronmicroscopy study. Brain Research 554, 237-243.

Blümcke, I., Weruaga, E., Kasas, S., Hendrickson, A.E. \& Celio, M.R. (1994). Discrete reduction patterns of parvalbumin and calbindin D-28k immunoreactivity in the dorsal lateral geniculate nucleus and the striate cortex of adult macaque monkeys after monocular enucleation. Visual Neuroscience 11, 1-11.

BLÜMCKE, I.\& Celio, M.R. (1992). Parvalbumin and calbindin D-28k immunoreactivities coexist within cytochrome oxidase-rich compartments of squirrel monkey area 18. Experimental Brain Research 92 , 39-45.

Braak, H. \& BachmanN, A. (1985). The percentage of projection neurons and interneurons in the human lateral geniculate nucleus. Human Neurobiology 4, 91-95.

Casagrande, V.A. (1994). A third parallel visual pathway to primate area V1. Trends in Neurosciences 17, 305-310.

CASAGRANDE, V.A. \& NoRTON, T.T. (1991). Lateral geniculate nucleus: A review of its physiology and function. In Vision and Visual Dysfunction, Vol. 4, The Neural Basis of Visual Function, ed. LeVENThal, E. \& Cronley-Dillon, J.R., pp. 41-84. London: Macmillan Press.

Cusick, C.G., Scripter, J.L., Darensbourg, J.G. \& Weber, J.T. (1993). Chemoarchitectonic subdivisions of the visual pulvinar in monkeys and their connectional relations with the middle temporal and rostral dorsolateral visual areas, MT and DLr. Journal of Comparative Neurology 336, 1-30.

DeFelipe, J. \& Jones, E.G. (1991). Parvalbumin immunoreactivity reveals layer IV of monkey cerebral cortex as a mosaic of microzones of thalamic afferent terminations. Brain Research 362, 39-47.

Diamond, 1.T., Fitzpatrick, D. \& SChmeChel, D. (1993). Calciumbinding proteins distinguish large and small cells of the ventral posterior and lateral geniculate nuclei of the prosimian galago and the tree shrew (Tupaia belanger). Proceedings of the National Academy of Sciences of the U.S.A. 90, 1425-1429.

Eckert, A., HartmanN, H., Forstl, H. \& Muller, W.E. (1994). Alterations of intracellular calcium regulation during aging and Alzheimer's disease in nonneuronal cells. Life Sciences 55, 2019-2029.

Fonseca, M., Soriano, E., Ferrer, l., Martinez, A. \& Tunon, T. (1993). Chandelier cell axons identified by parvalbumin-immunoreactivity in the normal human temporal cortex and in Alzheimer's disease. Neuroscience 55, 1107-1116.

Grosh, A. \& Shatz, C.J. (1992). Pathfinding and target selection by developing geniculocortical axons. Journal of Neuroscience 12, 39-55.

Glezer, I.I., HoF, P.R. \& MORGANE, P.J. (1992). Calretinin-immunoreactive neurons in the primary visual cortex of dolphin and human brains. Brain Research 595, 181-188.

Gutierrez, C. \& Cusick, C.G. (1994). Effects of chronic monocular enucleation on calcium binding proteins calbindin- $D_{28 \mathrm{k}}$ and parvalbumin in the lateral geniculate nucleus of adult rhesus monkeys. Brain Research 651, 300-310.

Hashikawa, T., Rausell, E., Molinari, M. \& Jones, E.G. (1991). Parvalbumin- and calbindin-containing neurons in the monkey medial geniculate complex: Differential distributions and cortical layer specific projections. Brain Research 544, 335-341.

HeizmanN, C.W. (1992). Calcium-binding proteins: Basic concepts and clinical implications. General Physiology and Biophysics 11, 411-425.

Heizmann, C.W. (1993). Calcium signaling in the brain. Acta Neurobiologiae Experimentalis 53, 15-23.

Heizmann, C.W. \& Braun, K. (1992). Changes in $\mathrm{Ca}^{2+}$-binding proteins in human neurodegenerative disorders. Trends in Neurosciences 15, 259-264.

HendRy, S.H.C. \& CARDER, R.K. (1993). Neurochemical compartmentation of monkey and human visual cortex: Similarities and variations in calbindin immunoreactivity across species. Visual Neuroscience 10, 1109-1120.

Hockfield, S., Tootell, R.B. \& Zaremba, S. (1990). Molecular differences among neurons reveal an organization of human visual cortex. Proceedings of the National Academy of Sciences of the U.S.A. 87, 3027-3031.

HockFIELD, S. \& SUR, M. (1990). Monoclonal antibody Cat-301 identifies $Y$-cells in the dorsal lateral geniculate nucleus of the cat. Journal of Comparative Neurology 300, 320-330.
JACoBowITZ, D.M. \& WINSKY, L. (1991). Immunocytochemical localization of calretinin in the forebrain of the rat. Journal of Com. parative Neurology 304, 198-218.

Johnson, J.K. \& CaSAGRANDE, V.A. (1995). Distribution of calciumbinding proteins within the parallel visual pathways of a primate (Galago crassicaudatus). Journal of Comparative Neurology 356, 238-260.

JONES, E.G. (1993). GABAergic neurons and their role in cortical plasticity in primates. Cerebral Cortex 3, 361-372.

JoNEs, E.G. \& HENDRY, S.H.C. (1989). Differential calcium binding protein immunoreactivity distinguishes classes of relay neurons in monkey thalamic nuclei. European Journal of Neuroscience 1, 222246.

Lachica, E.A. \& Casagrande, V.A. (1993). The morphology of collicular and retinal axons ending on small relay (W-like) cells of the primate lateral geniculate nucleus. Visual Neuroscience 10, 403-418.

LEICHNETZ, G.R. (1990). Preoccipital cortex receives a differential input from the frontal eye field and projects to the pretectal olivary nucleus and other visuomotor-related structures in the rhesus monkey. Visual Neuroscience 5, 123-133.

Livingstone, M. \& HuBEL, D. (1988). Segregation of form, color, movement, and depth: Anatomy, physiology, and perception. Science $\mathbf{2 4 0}$ 740-749.

MA, T.P., Cheng, H.-W., Czech, J.A. \& Rafols, J.A. (1990). Intermediate and deep layers of the macaque superior colliculus: A Golgi study. Journal of Comparative Neurology 295, 92-110.

Majoli, M., Galletti, C., SQuatruto, S., Battaglini, P.P. \& Riva SanSEVERINO, E. (1984). Projections from the cortex of the superior temporal sulcus to the dorsal lateral geniculate and pregeniculate nuclei in the macaque monkey. Archives italiennes de Biologie 122, 301309.

Mize, R.R., Luo, Q., Butler, G., Jeon, C.-J. \& Nabors, B. (1992a). The calcium binding proteins parvalbumin and calbindin-D $28 \mathrm{~K}$ form complementary patterns in the cat superior colliculus. Journal of Comparative Neurology 320, 243-256.

Mize, R.R., Luo, Q. \& Tigges, M. (1992b). Monocular enucleation reduces immunoreactivity to the calcium-binding protein calbindin $28 \mathrm{kD}$ in the Rhesus monkey lateral geniculate nucleus. Visual Neuroscience $9,471-482$.

Mize, R.R. \& Hockfield, S. (1989). Cat-301 antibody selectively labels neurons in the $\mathrm{Y}$-innervated laminae of the cat superior colliculus. Visual Neuroscience 3, 433-443.

Mize, R.R. \& Luo, Q. (1992). Visual deprivation fails to reduce calbindin $28 \mathrm{kD}$ or GABA immunoreactivity in the Rhesus monkey superior colliculus. Visual Neuroscience 9, 157-168.

MoORE, R.Y. (1993). Organization of the primate circadian system. Review. Journal of Biological Rhythms 8 (Suppl.) S3-S9.

Morecraft, R.J., Geula, C. \& Mesulam, M.M. (1992). Cytoarchitecture and neural afferents of orbitofrontal cortex in the brain of the monkey. Journal of Comparative Neurology 323, 341-358.

Mustari, M.J., FuChs, A.F., Kaneko, C.R. \& Robinson, F.R. (1994). Anatomical connections of the primate pretectal nucleus of the optic tract. Journal of Comparative Neurology 349, 111-128.

Pasteels, B., Rogers, J., Blachier, F. \& Pochet, R. (1990). Calbindin and calretinin localization in retina from different species. Visual Neuroscience 5, 1-16.

Rausell, E. \& Jones, E.G. (1991). Histochemical and immunocytochemical compartments of the thalamic VPM nucleus in monkeys and their relationship to the representation map. Journal of Neuroscience 11, 210-225.

STEIN, B.E. \& MEREDITH, M.E. (1993). Anatomical organization of the superior colliculus. In The Merging of the Senses, ed. GAzZANIGA M.S., pp. 41-49. Cambridge, London: A Bradford Book, The MIT Press.

Stichel, C.C., Singer, W. \& Heizmann, C.W. (1988). Light and electron immunocytochemical localization of parvalbumin in the dorsal geniculate nucleus of the cat: Evidence for coexistence with GABA. Journal of Comparative Neurology 268, 29-37.

Tigges, M. \& Tigges, J. (1993). Parvalbumin immunoreactivity in the lateral geniculate nucleus of rhesus monkeys raised under monocular and binocular deprivation conditions. Visual Neuroscience 10, 1043-1053.

Tunon, T., Insausti, R., Ferrer, I., Sobreviela, T. \& Soriano, E. (1992). Parvalbumin and calbindin D-28K in the human entorhinal cortex. An immunohistochemical study. Brain Research 589, 24-31. 